\title{
Overcoming the Barriers for Participation by the Disabled: An appraisal and global view of community-based rehabilitation in community development
}

\author{
Olaogun, M.O.B., Nyante, G.G.G., Ajediran, A.I. \\ Department of Physiotherapy, School of Allied Health Sciences, College of Health Sciences, University of Ghana \\ Correspondence \\ Matthew O.B. Olaogun, School of Allied Health Sciences, University of Ghana, PO Box KB-143, Korle-Bu, \\ Accra, Ghana・Email:mobolaogun@yahoo.co.uk
}

\begin{abstract}
SUMMARY
The discipline of rehabilitation developed after the Second World W ar. Some disabled people were reintegrated into the society due to advances in technical aids, appliances and assistive technology. The transfer of these aids and technology to developing countries was facilitated by the United Nations Organization (UNO). The results, however, did not get to the rural communities. The number of people with disability worldwide, and particularly in the developing countries, is increasing due to wars, conflicts, vehicular accidents, chronic diseases, mental impairment, birth defects and malnutrition. Many of these people face participation-restriction in activities of life. This paper appraises the emergence and the global view of community-based rehabilitation (CBR). The review and remodelling of $\mathrm{CBR}$ in developing countries, and its inclusion in community development will enhance the reintegration of the disabled individuals into the society.
\end{abstract}

KEY WORDS: disabled, community based rehabilitation, reintegration, community development

\section{INTRODUCTION}

At the end of World War II, many countries had large numbers of servicemen who had sustained various forms of disability. Since then, the number of people with disabilities has been increasing worldwide. Some other causes of disability include falls, vehicular accidents and chronic diseases. The participation of individuals with disabilities in activities and community participation is limited. Some disabled individuals, however, are able to reintegrate into their communities due to advances in technical aids, appliances and assistive technology.

A new specialty - rehabilitation, rapidly developed in the decades after the Second World War, and became the subject of substantial international research, development and technical assistance by governments and international non-government organizations. In 1951, the UNO established a Rehabilitation Unit, with the aim of facilitating the transfer of these new medical and technical advances to developing countries. The main aspects of the international assistance were training of rehabilitation specialists and technicians as a professional team and support for the construction of large urban-based rehabilitation centres. By the end of the 1960s, it was observed that this approach had only resulted in minimal rehabilitation service delivery in the capital cities, but was not reaching the vast numbers of disabled children and adults living in villages and slums.

In 1978, following a series of reviews and meetings, the World Health Organization (WHO) adopted the Alma Alta Declaration, shifting support from city-based hospitals and institutions to the community. The community-based rehabilitation (CBR) initiative eventually evolved (WHO/Disability, 2007). The World Health Organization has been very effective in developing guidelines for CBR, conducting regional and national workshops to promote CBR guidelines, and supporting member states to initiate $\mathrm{CBR}$ and/or strengthen existing CBR programmes. Some member countries are, however, yet to embrace the guidelines of WHO-CBR. In countries like Nigeria, rehabilitation services are either institution-based, within the cities or suburban communities, or form part of active 
outreach services to rural communities, supported by international agencies.

Community rehabilitation services in any form are yet to take off in many developing countries (Tinney et al, 2007). The consequences of civil wars, political upheavals and strife, in addition to poverty, as in Liberia, Sierra Leone, Rwanda, the Democratic Republic of Congo, have also increased the incidence of disabilities in the developing countries of Africa. There is, therefore, the need to explore a workable model for the rehabilitation of disabled individuals in the community as a means of overcoming the limitations imposed by the handicap. Full participation of the physically-challenged has been part of the United Nation's Standard Rules on the Equalization of Opportunities for Disabled People, which states under the Principles of Equal Rights that, the needs of each and every individual are of equal importance, and that those needs must be made the basis for the planning of societies. In addition, all resources must be employed to ensure that every individual has equal opportunities for full participation (United Nations, 1993). Many developing nations are signatories to the UN position. Ghana, for instance, came out with the National Disability Policy Document, which seeks to ensure the inclusion and full participation of disabled people in all spheres of social life (National Disability Policy Document, 2000). In spite of the policy, there are still many public facilities which are designed without consideration for people with disabilities. These include schools, offices, libraries, hospitals and other public facilities (Annor, 2002). Also roadside infrastructures, such as open gutters, and inaccessible vehicles further restrict their mobility. In a study conducted by Mock et al (2003), 33\% of the participants whose longterm injuries resulted in disability, had fallen into open street gutters.

In some developing nations, disability is often considered to be a punishment for wrong doing, witchcraft, an evil eye, the wrath of God/ the gods, or the ancestors' anger. Such a belief is a major cause of participationrestriction. It affects marriages, interpersonal relationships, mobility, employment, access to treatment and care, education, and attendance at social and religious functions (van Brakel et al, 2006).

The cultural and traditional norms, societal beliefs and values which perpetuate prejudice, discrimination and unequal opportunities constitute another major barrier to the participation of the physically-disabled in the African community. Some researchers contend that the primary problems facing disabled persons are the negative societal attitudes and beliefs (Waldie, 2002; Tomlinson and Abdi, 2003).

This paper explores the evolution of community-based rehabilitation into a community development model, that offers the hope of a good quality of life to the physicallychallenged, by providing or ensuring full participation in their rehabilitation affairs and in the society.

\section{The Meaning of Rehabilitation}

Rehabilitation is not only concerned with physical or functional restoration/compensation of individuals disabled by injury or disease. Attention is also given to the total quality of life in terms of wellness, happiness and satisfaction in fulfilling the demands needs capacities of human existence in orientation, freedom of movement, independence, expression of self (with respect to age, sex and culture), relationship and ability to ensure independent economic existence. After a serious injury, illness or surgery, one needs to recover slowly. There is the need to regain strength, to relearn skills or find new ways of doing things one did before. This is the process of rehabilitation.

Children who are born with disabilities need stimulation for development and adaptation - habilitation (Winnick, 1979), and those who acquire disabilities also need rehabilitation. Technically, therefore, rehabilitation is a creative procedure that includes the cooperative efforts of various medical specialists, and associates in other health, technical and environmental fields, to improve the physical, mental, social and vocational aptitudes of the disabled, with the objectives of preserving and improving their ability to live happily and productively on the same level, and with the same opportunities as their neighbours (Krusen et al, 1971; Olaogun, 2007). In other words, it is a process of decreasing the dependence of the disabled person, by developing to the greatest extent possible, the abilities needed for adequate functioning in his individual situation in the community (Helinder, 1984).

\section{Related Community-Based Disciplines}

Lucas and Giles (2003) identified 4 dimensions of public health - preventive medicine, social medicine, community health and community medicine.

Community health deals with the services that aim at protecting the health of the community. The intervention ranges from public sanitation, environmental hygiene, diseases vector control, health education, immunization and so on. Community rehabilitation deserves a niche in the scope of community health. Surveillance, monitoring 
of community health needs and the assessment of the impact of interventions are also part of community health practice.

Community medicine is synonymous with primary health care (PHC), which is the lowest level of health care delivery. This refers to health services that are provided at the community level. There are guides for primary and clinical diagnosis, care and administration of medicines. There are no facilities for surgery. Referrals are made to the comprehensive health centres ( $\mathrm{CHCs}$ ) or state/regional hospitals for advanced care and surgery. Community physicians, community health officers, nurses, community physiotherapists and other health care personnel are involved in providing care at the primary health care clinics (PHCs), comprehensive health centres (CHCs) and in old peoples' homes.

\section{Evolution of Rehabilitation Services}

A situation-analysis on prevalence and incidence of disability revealed a lower prevalence of disabilities in the developing countries, due to the short life span of disabled people (Helinder, 1984). The factor contributing to death is not the disability per se, but infectious diseases and diarrhoea. There is therefore a global need for improved rehabilitation services. Rehabilitation services, where available, have been active or passive, institution-based or on outreach programmes (Helinder, 1984; Olaogun, 1986; and Lucas and Giles, 2003).

\section{Types of Rehabilitation Services}

Active Rehabilitation Services imply functional training, schooling and vocational training, which lead to an independent and better social integration. Examples of where it is offered in Nigeria include the Children Development Centre, Surulere, Lagos and the Stella Obasanjo Child Trust Foundation, Abuja.

Passive Rehabilitation Services signify those which do not aim at independent and better social integration. These are offered in rehabilitation homes and care institutions, where people with disabilities are given shelter and food, but do not undergo any training programme (Olaogun et. al, 1992).

Institution-Based Rehabilitation (IBR): In this category, general or specialized services are offered in an institution or home for the disabled. General institutions include centres that provide services for people with all types of disability. Specialized ones include homes for children with physical disability, e.g., Atanda Olu School, Surulere, Lagos and Cheshire Home Oluyole, Ibadan, all in Nigeria. Rehabilitation Centre, Moniya, Ibadan, is also an institution-based rehabilitation center, with active rehabilitation services and vocational training for spinal cord injury victims. The institute also provides out-patient and in-patient services, and long-term boarding. An example of this is Modupe Cole Home for the Handicap, Akoka, Lagos. There are regular physiotherapy services for the cerebral palsy children in this home.

Outreach Services for Rehabilitation Professionals from foreign or local-based institutions advise the local authorities about the environmental, vocational and educational problems that can be dealt with, in order to ameliorate the situations/conditions facing people with disabilities. Decentralization of professional services to the community level, as far as the resources allow, are delivered locally. In Nigeria for instance, this has been done through mobile teams, camps and day-clinics, using comprehensive health centers or schools as contact points (Abereoje and Olaogun,1990). Some religious institutions on outreach programmes are also offering rehabilitation services in several states of the country.

With the analysis and definitions above, only very few disabled will receive rehabilitation services, particularly of IBR. In some developing countries, there are no rehabilitation services at all. Where they are available, rehabilitation services in the institutions do not provide social integration. Services provided were far from ideal. An alternative approach to IBR was then declared by WHO in 1978 - Community Based Rehabilitation (CBR) (Helinder, 1984, WHO, 2007). CBR has the notion that:

a. If rehabilitation is to reach all those in need in the developing countries, there must be a large-scale transfer of knowledge about disabilities and skills in the rehabilitation of people with disabilities to their families and members of the community.

b. For rehabilitation to be successful, communities must recognize and accept that people with disabilities have the same rights as other human beings. Rehabilitation therefore needs to aim at bringing about this required attitude- change in communities. It has been found that this change in attitude is most effectively brought about when communities themselves take on the task of rehabilitating their members who have disabilities. CBR is a strategy that seeks to ensure that people with disabilities are involved in the development of their 
community by having equal access to rehabilitation and other services and opportunities - health, education and income; as do other members of the society.

The targets of the CBR programme are: people with disabilities, families of people with disabilities, organizations of people with disabilities, local, regional (state) and national (federal) governments, international organizations, non-government organizations, professionals in health sciences and other fields and the private sector (business and industry)

The system components of the CBR include: technology, service delivery and community involvement and close cooperation with organizations of people with disabilities and parents of disabled children.

In a CBR programme, all the interventions that can be effectively done should be done, then referral services at higher levels should have professional inputs. Three levels of referrals were proposed: district, provincial and national. These can be translated to local, state and national levels, respectively.

At the district/local government level, diagnostic services should be available. If circumstances allow, each client in the CBR programme should be seen by a physician. The purpose is to confirm diagnoses and make sure that no medical treatment is neglected. In other words, comorbidity should not be neglected. There should be educational services for children and provision of resource teachers, vocational services for adults, vocational assessment and guidance, skill acquisition and short-term vocational training and job placement.

There should be provision of simple orthopaedic appliances and other adapted equipments. There is a need for an intermediate-level supervisor or a CBR manager, who can train the local supervisors, guide and supervise their work, manage referrals, maintain communications will all levels of service and manage the CBR programme.

Integrating CBR into Primary Health Care (PHC) may be considered, but $\mathrm{CBR}$ must be given due attention to make it effective. The PHC is the lowest level of medical service delivery in many developing countries, but it has not given the desired attention to CBR.

At the state level, CBR involves referral for: diagnostic services for more complex medical conditions; medical services for corrective surgery, e.g., ear-drum perforation, eye surgery, complicated fractures; drug treatment of therapy- resistant diseases; complex rehabilitation therapy for those not improved through community services; educational services, such as special education (schools for the blind and the deaf); long-term vocational training and provision of standard orthopaedic appliances.

At the national/federal level, there should be referral, as at the state level, for more complex medical diagnosis and very specialized medical services, complex rehabilitation services like spinal fusion and physiotherapy, educational services at institutions of higher learning for people with disabilities and vocational services (training in special vocational subjects unavailable at local and state levels).

Professionals will be involved in the delivery of complex rehabilitation services as well as in the training and supervision of personnel for district, provincial and national levels. There is therefore the need for the review of the present training curricula of various professional groups in order to prepare the graduands better for the additional responsibilities they will have in the referral system of a CBR programme.

It is suggested that the CBR programme be started from the district level, rather than from the national level, which can be wasteful. At national institutes, well-trained professionals are often occupied with simple levels that could be done by someone with less training.

The activities in CBR at the three levels include:

- Promotion of positive attitudes towards people with disabilities.

- Making public utility and offices accessible.

- Preventing causes of disabilities.

- Providing rehabilitation services.

- Facilitating education and training opportunities.

- Supporting local initiatives.

- Monitoring and evaluating CBR programmes.

- Supporting micro and macro income-generation opportunities.

\section{Community Involvement}

A rehabilitation programme based in the community must have its roots there. The community must be involved in its planning, implementation and evaluation. A community committee should be involved as a management group. The local government should provide the personnel and financing for it. The WHO rehabilitation unit does not provide consultancy services for periods longer than 3 months (Helinder, 1984).

In CBR programmes, it is important to have community organizations and informally involve some people with disabilities in an advisory capacity. 
Opinion leaders such as the religious leaders and traditional rulers should champion the demystification of our traditional norms and practices pertaining to disabilities.

\section{The CBR Global Review}

Twenty years after its introduction, a global consultation forum to review the state of CBR was called by WHO, in collaboration with the UNO, NGOs and disabled people's organizations. The consultation was hosted by the government of Finland, in Helsinki on May 25-28, 2003 (WHO, 2007).

The theme paper for the meeting noted that:

i. Because all communities differ in socioeconomic conditions, terrain, culture and political systems, there cannot be one model of CBR for the world.

ii. The focus of CBR has evolved from medical rehabilitation towards more comprehensive multisector approaches such as access to health care, education, vocational training, income generation programmes, community participation and inclusion.

\section{The New Model}

There are five key components which show the different sectors of the CBR strategy as a component of community development. They are health, education, livelihood, social and empowerment.

In health, attention is focussed on wellness promotion, disease prevention, medical care rehabilitation and use of assistive devices. The subsets of education are early childhood development, non-formal education, formal. Livelihood is concerned with skill development, selfemployment, waged-employment, financial services and social protection. The subsets of social components are personal assistance, relationship, marriage and family, culture, religion, arts, sports recreation, leisure and access to justice. On empowerment, the disabled individual is involved in social mobilization, political participation, selfhelp groups and disabled peoples' organizations (WHO, 2007). Lindoewood (2005) contended that by supporting and developing a network of disabled self-help groups, there is a systematic development structure through which medical therapeutics and other individualized services can be channelled with greater effectiveness. The disabled community are enabled to become part of the solution rather than remaining the problem. It is important to stress that public offices and utilities should provide access and protection to the physically-disabled.

\section{CONCLUSION}

The physically-disabled in most developing countries still face a lot of obstacles or barriers to full participation in their affairs and in the society. Most governments need to revisit the principles of WHO-CBR to provide equal opportunities for their citizens. The community-based rehabilitation principles should be involved as components of community development, which is essential for any meaningful government. Aside involving the disabled in the running of CBR, developing a strong disabled community network will also go a long way in sustaining the project and making the disabled part of the solution of overcoming the restriction in participation in all areas of human endeavour. Public offices and utilities should include provisions for accessibility. Aside the benefits of physical rehabilitation, the CBR encourages the participation of the physically-challenged in social rehabilitation. 'Bionic' vehicles can be provided and restricted for the use of the aged and the physicallychallenged. The community-based approach in reducing the barriers for participation by the physically- challenged is modifiable without neglecting the goals of the components of health, education, livelihood, social and empowerment.

CBR can play a significant contribution to the overall development of the country if politicians, administrators and professionals pay attention to the infrastructure and training needs which are necessary to fulfill the potential of the programme.

\section{References}

Abereoje, O.K. and Olaogun, M.O.B. (1990) An appraisal of community physiotherapy practices in Nigeria JNSP 9, pp.22-27.

Annor, J. (2002). People-to-People International (NGO) Ghana, 2002 conference proceedings.

http://www.csun.edu/cod/conf/2002/ proceedings/98.htm.

Helinder, E. (1984) The principles of community-based rehabilitation. Quaderni di cooperazione sanitaria - Health Cooperation 11, pp.35-41.

Krusen, F.H., Kottke, F.J. and Elwood, P.M. (1971) Handbook of Physical Medicine and Rehabilitation. The American Rehabilitation Foundation. Toronto, WB Saunders, pp.1-10.

Lindoewood, P. (2005) Community-based rehabilitation and disability self-help groups. Health care information for all by 2005: drtc@phonecoop.coop.

Lucas, A.O. and Giles, H.M. (2003) Short Text Book of Public Health $4^{\text {th }}$ ed., pp.1-10. 
Mock, C.N., Boland, E., Acheampong, F. and Adjei, S. (2003) Long-term injury related disability in Ghana.Disability and Rehabilitation, 25 (13), pp.732-741.

National Disability Policy Document- Ghana(2000). http://www.disability.dk/site/viewdoc.php?doc_id=208\&se ction_id $=6$.

Olaogun, M.O.B. (1986) The Oyo State Community Physiotherapy Scheme: Preventive and promotive measure in Nigeria. Physiotherapy Practice 2, pp.174-176

Olaogun, M.O.B., Olaogun, A.A.E. and Awojulu, S.O. (1992) Incidence of vesico vaginal fistula in an urban hospital in Nigeria - the need for physiotherapeutic intervention. JNSP 7(1), pp.32-36.

Tinney, M.J., Chiodo, A., Haig, A. and Wiredu, E. (2007) Medical rehabilitation in Ghana. Disability \& Rehabilitation 29(11), pp.921-927.

Tompett, J. (2007) CBR in Nassarawa State: Presentation at the 47th Annual Conference of the Nigeria Society of Physiotherapy, Mallam Amino Kano Teaching Hospital, Kano.

Tomlison, S. and Abdi, O.A. (2003) Disability in Somaliland. Disability and Society 18(7), pp.911- 920.
United Nations (1993) Standard rules on the equalization of opportunities for disabled people.

http:// www.un.org/documents/ga/res/48/a48r096.htm.

van Brakel, W.H., Anderson, A.M., Mutatkar, R.K., Bakirtzief, Z., Nicholls, P.G and Raju, M.S. (2006) The participation scale - measuring a key concept in public health. Disability and Rehabilitation 28(4), pp.193-200.

Waldie, E. (2002) Triumph of the Challenged. Conversations with especially-able people. Ilminister, Somerset, Purple Field Press.

Winnick, J.P. (1979) Early Movement, Experiences and Development - habilitation and remediation, Toronto, W.B. Saunders Co. pp.1-9.

World Health Organization (1969) Expert Committee on Medical Rehabilitation. World Health Organization Technical Report Series 419, pp.1-23.

WHO/Disability - Community-Based Rehabilitation, (2007). www.who.int/disabilities/cbr/matrix/en/index.html; www.african.org/saconference.html. 